\title{
Numerical analysis of the states of stress in the steel-titanium bimetal during cyclic bending
}

\author{
Grzegorz Robak ${ }^{1, *}$ and Artur Cichański ${ }^{2}$ \\ ${ }^{1}$ Opole University of Technology, ul. Mikolajczyka 5, 45-270 Opole, Poland \\ ${ }^{2}$ University of Science and Technology in Bydgoszcz, Al. prof. S. Kaliskiego 7, 85-796 Bydgoszcz, Poland
}

\begin{abstract}
This paper presents the results of experimental study into steel-titanium bimetal obtained by means of explosive welding, which involved the development of fatigue cracks. A particular emphasis in the report was placed on the analysis of development of the crack in the area in which the two metals are joined. The study was accompanied by a numerical analysis of the distribution of stresses in the weld area in terms of the elastic-plastic characteristics. The numerical analysis performed in terms of the elastic-plastic characteristics demonstrated that the titanium layer is completely plasticized as a result of the acting loading, when the crack is still located in the steel part of the examined plater.
\end{abstract}

\section{Introduction}

Composite materials are a common group of construction materials that allow to combine the properties of materials with significantly different strength properties and chemical com-position. There are many types of composite materials as well as manufacturing processes.

One of the ways to obtain a composite resulting from merging e.g. steel with titanium is explosion welding [1]. This process enables to combine materials, such as, e.g., steel-titanium, steel-zirconium or steel-aluminium, which cannot be combined using other methods or are very difficult to combine. During the detonation of the explosive placed on the cladding (e.g., titanium, zirconium), a detonation wave is created whose front moves continuously across the cladding. Plates collide at the front of the detonation wave, resulting in a lasting bond. Due to the high dynamics of detonation, the cladding is deformed to form a permanent bond with the substrate, usually in a corrugated shape. The shape of the bond, i.e., height and density of the wave, depends largely on detonation parameters and the thickness of the combined layers. Bimetals made in this way are used in process and electric power apparatus, such as heat exchangers, reactors, columns, pipes, and others [2-6]. Due to the high speed of creating a bond between the metals during explosion bonding, the bonding zone has a heterogeneous structure $[3,7,8]$ which can affect mechanical properties, in particular resistance to cracking.

It is necessary to conduct testing in order to determine the behaviour of these materials under certain loading conditions. It is also important to know the mechanisms associated with the growth of cracks, particularly in the bonding site.

This paper presents the results of experimental studies regarding the analysis of the growth of fatigue cracks in a bimetal made of two layers of steel $(\mathrm{S} 355 \mathrm{~J} 2+\mathrm{N})$ and titanium (Grade 1), with particular attention to the behaviour of the growth of cracks within the bond site in tension - compression and cyclic bending tests.

\section{Experimental research}

Experimental studies included tension cyclic bending with a controlled displacement. The growth of cracks was recorded using a stereomicroscope with a maximum magnification of $x 45$ connected to the camera. Specimen made of steel-titanium bimetal was used in the study, unilaterally notched in the steel part by spark erosion, shown in Fig. 1. Specimen was made of plated sheet obtained from the corner of the bimetallic plate. After the welding process, the sheet has been subjected to heat treatment by annealing at $600^{\circ} \mathrm{C}$ for $90 \mathrm{~min}$, then cooled in the furnace to the temperature of $300^{\circ} \mathrm{C}$ at a rate of $100^{\circ} \mathrm{C} / \mathrm{h}$. Cooling in the open air was the final stage. Mechanical properties and chemical composition of bimetal components are shown in Tables 1 and 2 .

Table 1. Mechanical properties of the bimetal.

\begin{tabular}{|c|c|c|c|c|}
\hline Material & $\begin{array}{c}\mathrm{R}_{\mathrm{e}} \text { (steel), } \\
\mathrm{R}_{0,2} \text { (titanium), } \\
\mathrm{MPa}\end{array}$ & $\mathrm{R}_{\mathrm{m}}, \mathrm{MPa}$ & $\mathrm{E}, \mathrm{GPa}$ & $v$ \\
\hline $\begin{array}{c}\text { Steel } \\
\text { S355J2+N }\end{array}$ & $382-395$ & $598-605$ & $206-220$ & $\begin{array}{c}027- \\
0.30\end{array}$ \\
\hline $\begin{array}{c}\text { Titanium } \\
\text { Grade } 1\end{array}$ & $189-215$ & $308-324$ & $100-105$ & $\begin{array}{c}0.37- \\
0.39\end{array}$ \\
\hline
\end{tabular}

*orresponding author: g.robak@po.opole.pl 
Table 2. Chemical composition of the bimetal.

\begin{tabular}{|c|c|c|c|c|c|c|}
\hline Material & \multicolumn{7}{|c|}{ Steel S355J2+N } \\
\hline $\begin{array}{c}\text { Chemical } \\
\text { element }\end{array}$ & $\mathrm{C}$ & $\mathrm{Si}$ & $\mathrm{Mn}$ & $\mathrm{P}$ & $\mathrm{S}$ & $\mathrm{Cu}$ \\
\hline $\begin{array}{c}\text { Max. } \\
\text { contents, } \\
\% \text { weight }\end{array}$ & 0.22 & 0.55 & 1.60 & 0.025 & 0.025 & 0.45 \\
\hline Material & \multicolumn{7}{|c|}{ Titanium Grade 1 } \\
\hline $\begin{array}{c}\text { Chemical } \\
\text { element }\end{array}$ & $\mathrm{C}$ & $\mathrm{Fe}$ & $\mathrm{H}$ & $\mathrm{N}$ & $\mathrm{O}$ & $\mathrm{Ti}$ \\
\hline $\begin{array}{c}\text { Max. } \\
\text { contents, } \\
\% \text { weight }\end{array}$ & 0.10 & 0.20 & 0.015 & 0.03 & 0.18 & 99.50 \\
\hline
\end{tabular}
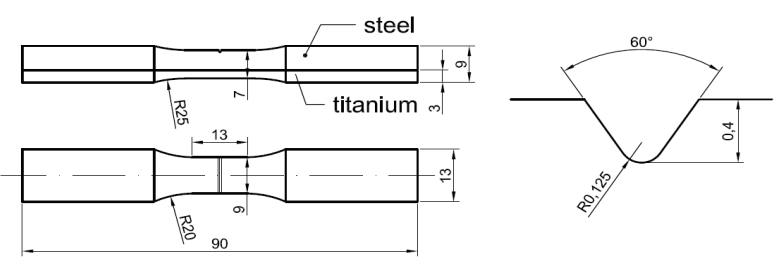

Fig. 1. Shape and dimensions of the notched specimen for the cyclic bending test.

As a result of explosion bonding, the bond between steel and titanium in the studied bi-metal takes an undulating shape with variable parameters [7]. Fig. 2 shows a diagram of the steel-titanium bond with indicated wave height in the specimen subjected to cyclic bending. a)



b)

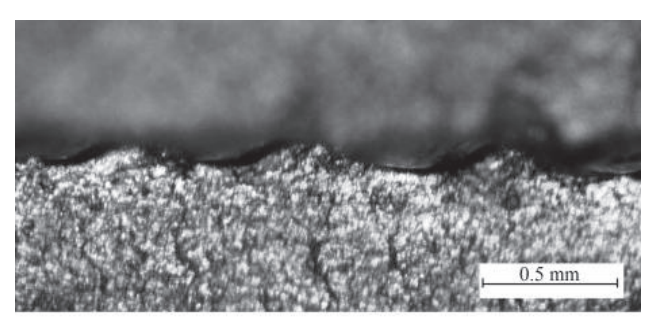

Fig. 2. a) Diagram of the steel-titanium bond on a specimen subjected to cyclic bending (the height of the titanium layer: 3 $\mathrm{mm}$, the height of the steel layer: $6 \mathrm{~mm}$, the height of wave in the bond zone for the studied specimen $0.184 \mathrm{~mm}$ ); b) Image $(\mathrm{x} 30)$ of the fracture of the test specimen with visible bonding in the form of a wave.

Experimental studies were carried out for one types of load. Specimens were subjected to cyclic bending at a controlled displacement. The study was carried out at a fixed frequency $\mathrm{f}$ equal to $7 \mathrm{~Hz}$. Displacement amplitudes $\Delta \mathrm{l}$ were taken at levels of $\Delta \mathrm{l}=2.4 \mathrm{~mm}, \Delta \mathrm{l}=$ $2.6 \mathrm{~mm}, \Delta \mathrm{l}=2.7 \mathrm{~mm}$ and $\Delta \mathrm{l}=2.9 \mathrm{~mm}$, with corresponding initial values of bending moments $\mathrm{M}_{\mathrm{b} 0}=$ $13.0 \mathrm{Nm}, \mathrm{M}_{\mathrm{b} 0}=14.4 \mathrm{Nm}, \mathrm{M}_{\mathrm{b} 0}=15.2 \mathrm{Nm}$ and $\mathrm{M}_{\mathrm{b} 0}=16.0$
Nm. Since the force took place at a constant displacement $\Delta \mathrm{l}$, the values of bending moments changed during crack propagation as a result of decreasing sectional area of specimens.

Fig. 3 shows the change in the values of bending moments as a function of the crack length a. Testing was interrupted when the crack after exceeding the bond zone reached the length of $1.5 \mathrm{~mm}$. As the result of twice lower value of Young's modulus for titanium, the remaining section of the specimen showed much lower stiffness, which prevented further study. The dashed line in Fig. 3 is the boundary between the substrate (steel) and cladding (titanium).

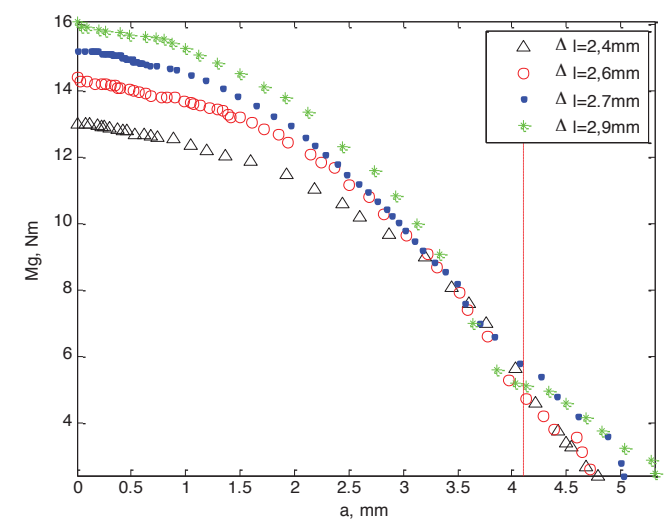

Fig. 3. The change of the values of bending moments in the specimens subjected to cyclic bending as a function of the crack length a.

\section{Analysis of the experimental results}

Fig. 4 shows the resulting graphs of the change of fatigue crack length a in function of the number of cycles $\mathrm{N}$ for specimens subjected to cyclic bending. The difference in the initiation and further propagation of cracks on both sides of specimens did not exceed $6 \%$, so it was decided to measure the growth of cracks on only one side of specimens. Note that the growth of cracks in the bond zone of two materials (dashed line, Fig. 4) followed without much difference despite changes in material properties and an increase in hardness of the material (titanium) in the bond zone [7].

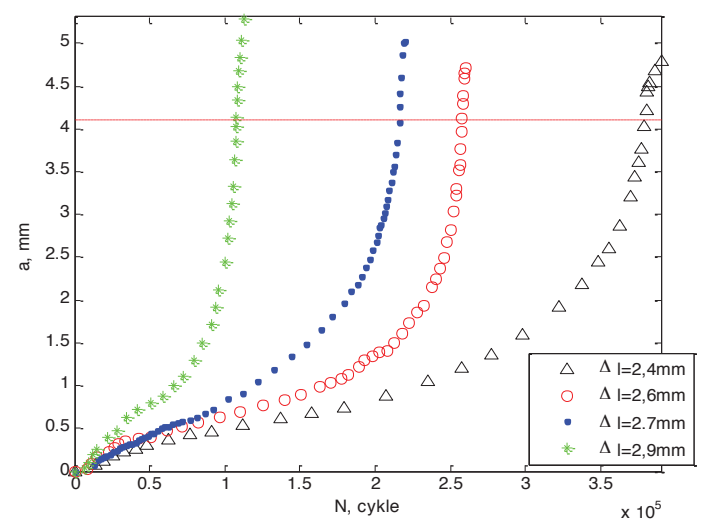

Fig. 4. Fatigue crack length a as a function of the number of cycles $\mathrm{N}$ for four displacement amplitudes $\Delta \mathrm{l}$. 
A reduction in the propagation rate was observed in the last phase of the growth of the crack $(\mathrm{a}=4.5-5.0 \mathrm{~mm})$, which can be explained by formation of large zones of plastic deformations visible on the surface of the specimen and a significant decrease in the amplitude of the bending moment.

The growth of cracks took place in the direction perpendicular to the axis of the specimen (Fig. 5a-b). However, at a distance of $0.1 \mathrm{~mm}$ from the connection line, the crack changed the direction by about $30^{\circ}$, assuming the direction perpendicular to the surface of the wave forming the bond (Fig. 5c-d).

This observation is consistent with the well-known knowledge of the directions of propagation of fatigue cracks [9].

After crossing the bond within $0.15 \mathrm{~mm}$, the crack again changed its direction to perpendicular to the axis of the specimen (Fig. 5e-f). Changing the direction of crack propagation was observed for each specimen irrespective of the load level, wherein the angle varied depending on the arrangement of the bond wave in a given specimen. Deflection in the direction of crack propagation may be due to changes in material properties within the bond zone.

a)

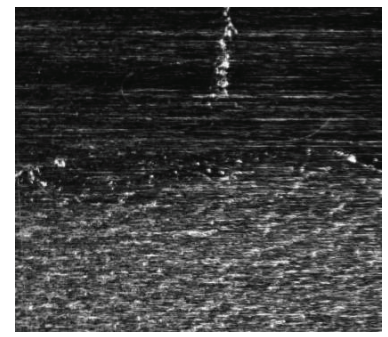

c)

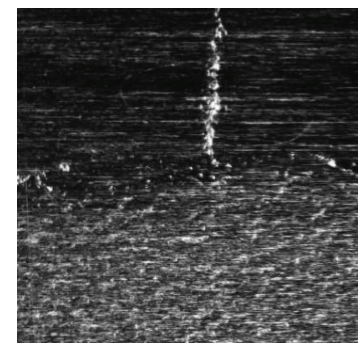

e)

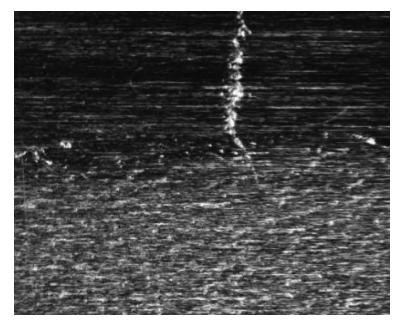

f)

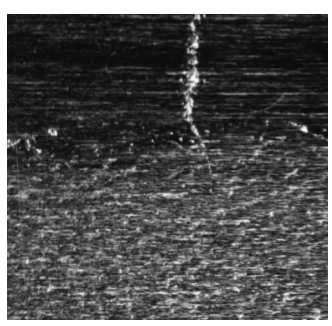

Fig. 5. Images of propagating the cracks for the load amplitude $\Delta \mathrm{l}=2.4 \mathrm{~mm}$ a-b) propagation direction perpendicular to the axis of the specimen, c-d) a change in the direction of propagation, e-f) propagation of the crack in titanium.

Fig. 6 shows graphs of propagation velocity as a function of crack length for the four amplitudes of displacement $\Delta 1$.

It can be noted in the graphs shown that the propagation rate increases with the increase of the displacement amplitude.

a)

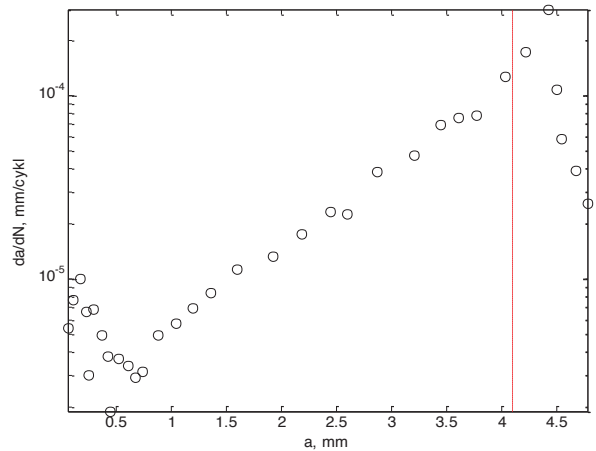

b)

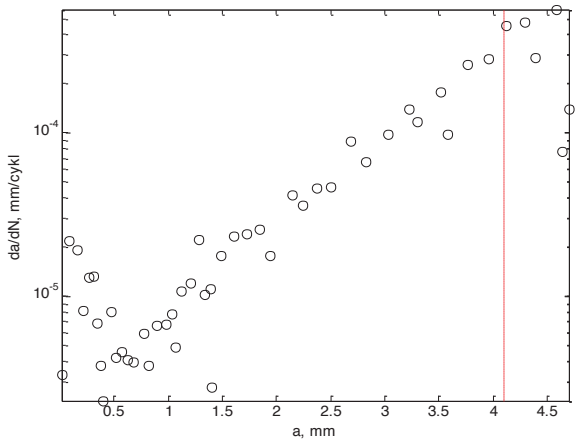

c)

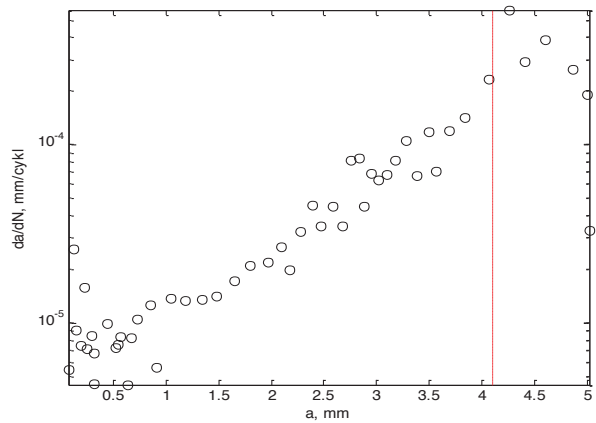

d)

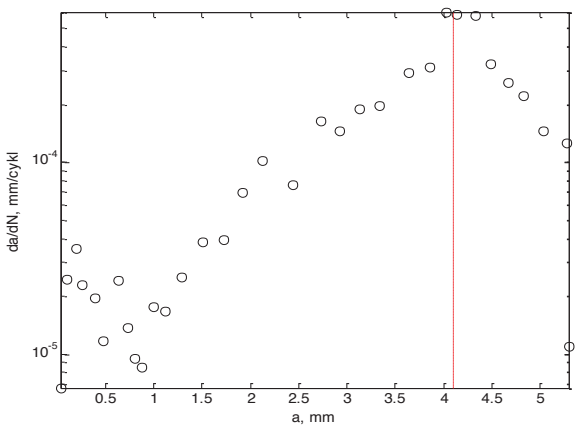

Fig. 6. Graphs of the crack propagation rate as a function of crack length for specimens subjected to cyclic bending and four displacement amplitudes: a) $\Delta \mathrm{l}=2.4 \mathrm{~mm}$, b) $\Delta \mathrm{l}=2.6 \mathrm{~mm}$, c) $\Delta \mathrm{l}=2.7 \mathrm{~mm}$, and d) $\Delta \mathrm{l}=2.9 \mathrm{~mm}$. 
However, the crack growth rate varies during the whole period of propagation. In the initial stage of crack growth, i.e., from zero to the length of the crack of about $0.2 \mathrm{~mm}$, the propagation rate (Fig. $6 \mathrm{~d}$ ) reaches the $\Delta \mathrm{l}=$ $2.9 \mathrm{~mm}$ equal to about $\mathrm{da} / \mathrm{dN}=0.3 \cdot 10^{-4} \mathrm{~mm} /$ cycle, and then the speed is reduced to a value of $\mathrm{da} / \mathrm{dN}=0.1910^{-4}$ $\mathrm{mm} /$ cycle in the range of $0.2 \mathrm{~mm}$ to $0.5 \mathrm{~mm}$. Starting from the length of the crack of $0.5 \mathrm{~mm}$, the propagation rate increases uniformly, reaching the maximum value in the material bond zone equal to $\mathrm{da} / \mathrm{dN}=0.29 \cdot 10^{-3}$ $\mathrm{mm} /$ cycle. After it is exceeded, the propagation rate decreases again, which is caused by a sharp reduction in bending moment and a decrease in stiffness of the specimen. The same variation of propagation rate was observed for other levels of the displacement amplitude $\Delta 1$. The phenomenon of the decrease in the growth rate of crack propagation after its initial rapid growth may be due to the occurrence of compressive residual stresses $[10,11]$ occurring in the titanium layer as the result of heat treatment.

\section{Numerical analysis}

Nonlinear FEM analyses were performed in ANSYS 18.0 environment. Cyclic properties of both metals were used to describe plastic behaviour of materials Table 2 . Computations were performed as two-dimensional problem in plane strain conditions.

Table 2. Cyclic properties of the bimetal.

\begin{tabular}{|c|c|c|}
\hline Material & $\mathrm{K}^{\prime}, \mathrm{MPa}$ & $\mathrm{n}{ }^{\prime}$ \\
\hline $\begin{array}{c}\text { Steel } \\
\text { S355J2+N }\end{array}$ & 720.94 & 0.1258 \\
\hline $\begin{array}{c}\text { Titanium } \\
\text { Grade 1 }\end{array}$ & 190 & 0.0641 \\
\hline
\end{tabular}

Numerical simulations were performed for 6 different crack length $\mathrm{a}=4.218 \div 4.786 \mathrm{~mm}$ observed in last phase of crack development during test made with displacement amplitude $\Delta \mathrm{l}=2.4 \mathrm{~mm}$. The force values recorded during test for each crack length was converted to bending moment and shear force taken as boundary conditions for FEM analysis. The crack tip was modeled as a half of an arc of a radius $10 \mu \mathrm{m}$. In the computations there were used second order 8 nodes two-dimmensional finite elements PLANE183 [12]. In order to ensure the regularity of the dividing grid in the specimen model in the vicinity of the crack tip, a circular subarea divided into 4 quarters of appropriately selected lengths of edges was introduced (Fig. 7). The subarea thus prepared was mapped meshed [13]. In order to transition from the rounded edge of the crack tip subarea to the straight edges across of rest of the specimen model, a transition subarea was introduced (Fig. 7). This transition subarea was free meshed [14]. Along the $\alpha=0^{\circ}$ direction FE size increases proportionally to the radius increase so as to maintain a homogeneous aspect ratio (Fig. 9a). Map of the opening stress $\sigma_{22}$ near the crack tip for $\mathrm{a}=4.217 \mathrm{~mm}$ is shown in the Fig. 9a). Map of the opening stress $\sigma_{22}$ in the crack tip area for $\mathrm{a}=4.217 \mathrm{~mm}$ is shown in the Fig. 9b).

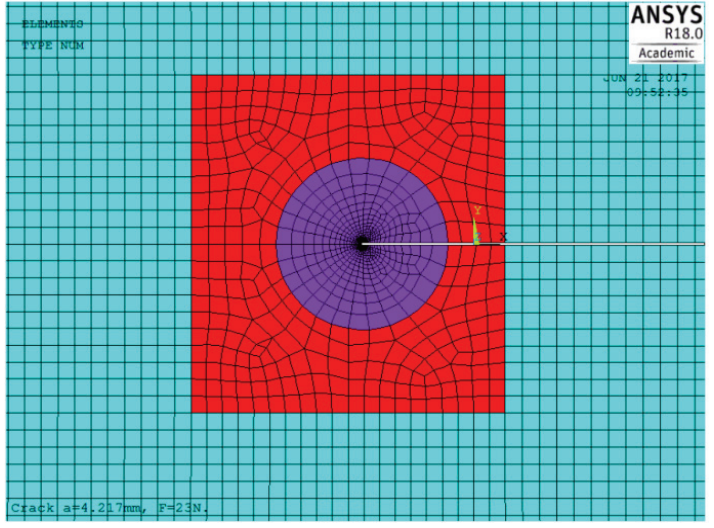

Fig. 7. Mesh morphology in crack tip area.

For the FEM analysis there is influence of the number of FE between the crack tip and the maximum location of the opening stress $\sigma_{22}$ along the $\alpha=0^{\circ}$ direction on the stress distribution [15]. In the model there is $7 \mathrm{FE}$ between the crack tip and the stress maximum location (Fig. 9a). In contrast to the radial direction, in the angular direction the FE size does not affect the stress distribution in front of the crack at $\alpha=0^{\circ}$ [15].

On the map of the opening stress $\sigma_{22}$ in the crack tip area Fig. 9b) the titanium layer is strongly emphasized by relative high stress values.

The stresses in the titanium layer are close to the plastic limit for this material (Fig. 8). This results in an increase in the opening stress $\sigma_{22}$ gradient in the steel part of specimen.



Fig. 8. Normalized opening stress distribution across of specimen width in crack direction.

The value of the maximum opening stresses $\sigma_{22}$ reaches the highest level at the distance about $0.018 \mathrm{~mm}$ from crack tip (Fig. 10). The values of maximum opening stresses $\sigma_{22}$ changes in range from $2.58 \div 2.8 \sigma_{0}$ with the change of fatigue crack length from $\mathrm{a}=4.786 \mathrm{~mm}$ to $\mathrm{a}=4.218 \mathrm{~mm}$. The maximum opening stresses decrease with decrease of distance to a free surface of the specimens. Intensity of this decrease is higher for deeper cracks (e.g. $a=4.786 \mathrm{~mm}$ ) than for shallower cracks (e.g. $\mathrm{a}=4.217 \mathrm{~mm}$ ). 
a)

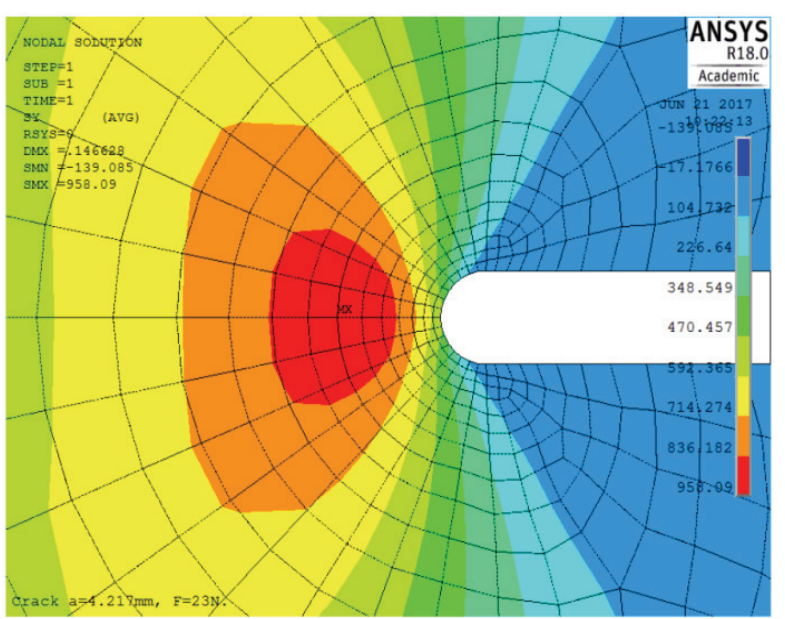

b)

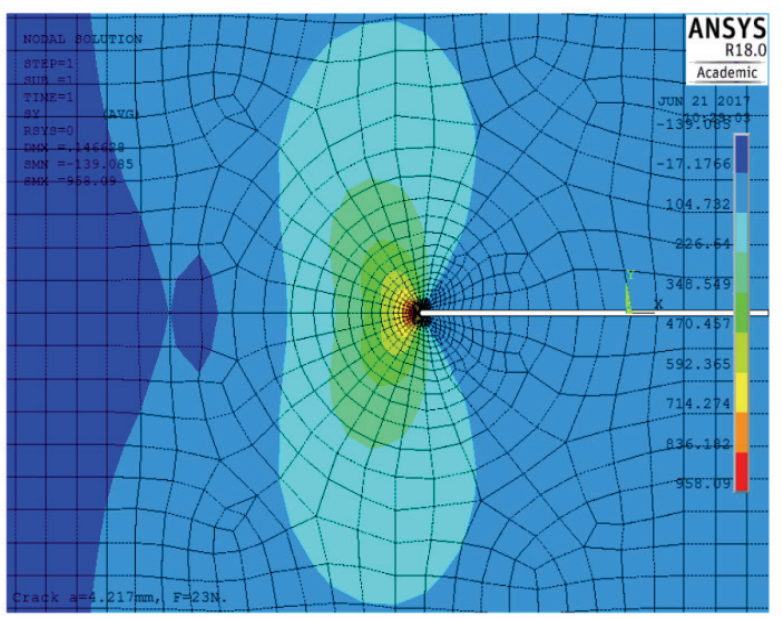

Fig. 9. Map of the opening stress $\sigma 22$ for $\mathrm{a}=4.217 \mathrm{~mm}$ : a) near the crack tip; b) in the crack tip area.

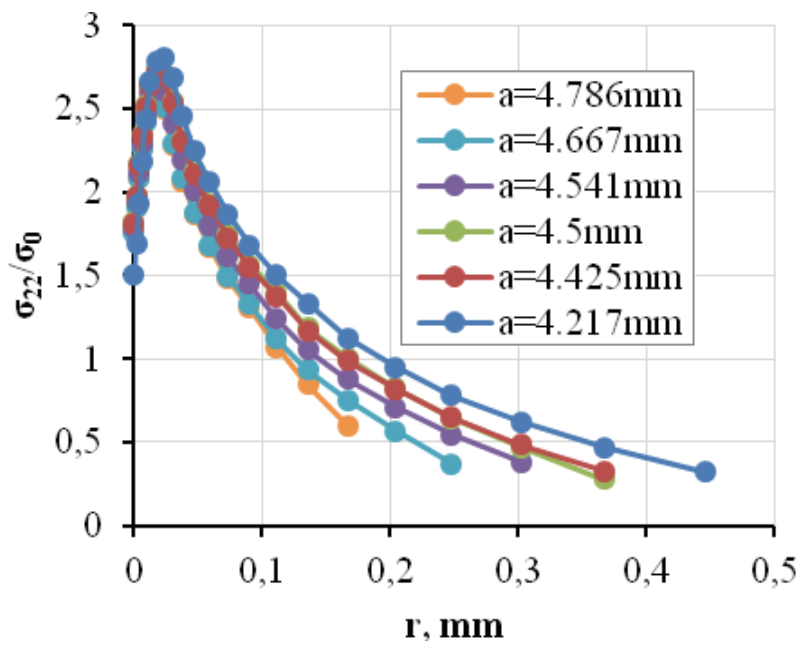

Fig. 10. Normalized opening stress distribution near the crack tip.

\section{Conclusions}

As a result of the research into steel-titanium bimetal, it was concluded that the occurrence of the plastic deformation fields in the steel before the cracking front did not result in a considerable stratification of the joint under the effect of a load comprising cyclically varied bending with a controlled value of the displacement. However, we noted a two-times change in the direction of the crack propagation in the area of the joint. The crack changed its direction in the steel component to perpendicular to the line of the joint and after it was trespassed, in the titanium section the direction was again perpendicular in relation to the axis of the sample. The numerical analysis performed in terms of the elasticplastic characteristics demonstrated that the titanium layer is completely plasticized as a result of the acting loading, when the crack is still located in the steel part of the examined plater. We also noted an irregular change in the velocity of the crack propagation during its development, which can be attributed to the occurrence of residual stresses resulting from the thermal machining of bimetals.

\section{References}

1. S. Akbari Mousavi, S. Al-Hassani, A. Atkins, Mater. Des. 29, 1334-1352 (2008)

2. H. Dyja, A. Maranda, R. Trebliński, Wydawnictwo Wydziału Metalurgii $i$ Inżynierii Materiałowej Politechniki Częstochowskiej (2001)

3. S. Król, R. Bański, Z. Szulc, A. Gałka, Adv. Mater. Sci. 7, 50-56 (2007)

4. L. Bower, J. Banker, Proceedings of Corrosion Solutions Conference, (2003)

5. G. Young, Hydrocarbon Eng. (2005)

6. K. Bujis, Super Yacht Ind. 3/5, 70-73 (2008)

7. A. Karolczuk, M. Kowalski, R. Bański, F. Żok, Int. J. Fatigue 48, 101-108 (2013)

8. S. Akbari Mousavi, P. Farhadi Sartangi, Mater. Sci. Eng. A-Struct. Mater. Prop. Microstruct. Process, 494, 329-336 (2008)

9. Ł. Pejkowski, D. Skibicki, J. Sempruch, Stroj VestnJ. Mech. E, 60/9, 549-560 (2014)

10. A. Karolczuk, K. Kluger, M. Kowalski, F. Żok, G. Robak, Materials Science Forum 726, 125-132 (2012)

11. A. Karolczuk, M. Kowalski, K. Kluger, F. Żok, Arch. Metall. Mater. 59, 1129-1133 (2014)

12. A. Cichański, Proceedings of 17th International Conference on Engineering Mechanics, 79-82 (2011)

13. A. Cichański, Proceedings of 22nd International Conference on Engineering Mechanics, 110-113 (2016)

14. A. Cichański, AIP Conference Proceedings 1822, (2017)

15. M. Graba, J. Gałkiewicz, J. Theor. Appl. Mech. 45, 225-237 (2007) 